Tropical Journal of Pharmaceutical Research October 2021; 20 (10): 2049-2054

ISSN: $1596-5996$ (print); 1596-9827 (electronic) (C) Pharmacotherapy Group, Faculty of Pharmacy, University of Benin, Benin City, 300001 Nigeria.

\title{
MiR-16 exacerbates neuronal cell growth and inhibits cell apoptosis by targeting AKT3 in cerebral ischemia injury
}

\author{
Yijun Song ${ }^{1 *}$, Bo Wang ${ }^{2}$ \\ ${ }^{1}$ Department of Internal Neurology, ${ }^{2}$ Department of Rehabilitation Medicine, Penglai Traditional Chinese Medicine Hospital of \\ Yantai City, Yantai City 265600, China \\ *For correspondence: Email: tuanyefu419794@163.com
}

\begin{abstract}
Purpose: To evaluate the role of miR-16 in ischemic neuronal injury. Methods: An oxygen-glucose deprivation (OGD) model of ischemic neuronal injury was established in human brain cortical neuron $\mathrm{HCN}-2$ cell line via hypoxic treatment. The mRNA or protein expressions of miR-16, AKT3, Bax and Bcl-2 were assessed by quantitative real time-polymerase chain reaction (qRT$P C R)$ or western blot assay. Targetscan online software was applied to predict potential targets of miR16. Cell proliferation was measured by CCK-8 assay while the relationship between miR-16 and AKT3 was determined by Luciferase reporter assay.

Results: MiR-16 was overexpressed after OGD treatment. MiR-16 overexpression significantly promoted the proliferation of cortical neurons and inhibited their apoptosis, while miR-16 inhibition produced an opposite effect. The expression of AKT3 was increased after miR-16 inhibition, but it was decreased when miR-16 was overexpressed. In addition, luciferase reporter gene results showed that miR-16 targeted AKT3. Functional experiments showed that AKT3 overexpression reversed the effect of miR-16 overexpression on ischemic injury.

Conclusion: MiR-16 regulates neuronal cell growth and cell apoptosis through AKT3 expression. These results present new potential therapeutic targets for the treatment of cerebral ischemic stroke.
\end{abstract}

Keywords: Cerebral ischemic injury, Oxygen-glucose deprivation, miR-16, AKT3

\begin{abstract}
This is an Open Access article that uses a funding model which does not charge readers or their institutions for access and distributed under the terms of the Creative Commons Attribution License (http://creativecommons.org/licenses/by/4.0) and the Budapest Open Access Initiative (http://www.budapestopenaccessinitiative.org/read), which permit unrestricted use, distribution, and reproduction in any medium, provided the original work is properly credited.
\end{abstract}

Tropical Journal of Pharmaceutical Research is indexed by Science Citation Index (SciSearch), Scopus, International Pharmaceutical Abstract, Chemical Abstracts, Embase, Index Copernicus, EBSCO, African Index Medicus, JournalSeek, Journal Citation Reports/Science Edition, Directory of Open Access Journals (DOAJ), African Journal Online, Bioline International, Open-J-Gate and Pharmacy Abstracts

\section{INTRODUCTION}

Cerebral ischemia, a common cerebrovascular problem, is a refractory disease that seriously endangers human health, and it is a major cause of permanent disability in adults [1]. It is associated with high morbidity, mortality and recurrence, as well as slow recovery [2]. In the pathogenesis of stroke, ischemia-reperfusion causes serious damage to the affected neurons
[3]. Neuronal apoptosis is a major cause of cerebral ischemic injury. Thus, inhibition of apoptosis is important in cerebral ischemic injury treatment. MicroRNAs (miRNAs) affect gene expression through inhibition of translation or induction of mRNA degradation by hybridizing with the 3'-UTR of target genes at posttranscriptional level [4]. Studies have indicated that the expressions miRNAs are altered in cerebral ischemia [5]. 
It has been reported that miR-16 acted as a tumor suppressor by inhibiting tumor progression in several cancers, including OSCC, breast cancer and HCC [6]. However, miR-16 also improved radiosensitivity, or inhibited cell apoptosis and enhanced cell proliferation in prostate cancer and polycystic ovarian syndrome $[7,8]$. Thus, it may be hypothesized that miR-16 expression is tissue-specific.

The AKT kinases are considered as cell signaling regulators in response to insulin and growth factors [9]. In particular, AKT serine/threonine kinase 3 (AKT3) relates to cell proliferation, differentiation, apoptosis and tumorigenesis [10]. In this study, the roles of miR-16 and AKT3, and the potential mechanism involved in cerebral ischemia injury were investigated.

\section{EXPERIMENTAL}

\section{Cell culture}

Human brain cortical neuron $\mathrm{HCN}-2$ cell line was purchased from ATCC, and cultured in DMEM (Sigma) containing $10 \% \mathrm{FBS}$ at $37^{\circ} \mathrm{C}$ incubator with $5 \% \mathrm{CO}_{2}$.

\section{OGD model}

To simulate ischemia-like conditions in vitro, an OGD model was established using $\mathrm{HCN}-2$ cell line. The cells were exposed to $1 \% \mathrm{O}_{2} / 94 \%$ $\mathrm{N}_{2} / 5 \% \mathrm{CO}_{2}$ conditions in glucose-free Hanks' balanced salt solution (Invitrogen) for $4 \mathrm{~h}$.

\section{Cell transfection}

The AKT3 small interfering RNA (siRNA-AKT3), miR-16 mimic and inhibitor, as well as controls were obtained from ThermoFisher Scientific (Shanghai, China). The AKT3 overexpressed plasmid (pcDNA3.1-AKT3) and the control plasmid (pcDNA3.1-NC) were obtained from Shanghai GenePharma. The transfected cells were cultivated in 6-well plate overnight. Lipofectamine 2000 (Invitrogen) was performed for cell transfection.

\section{Cell counting kit-8 (CCK-8) assay}

Cells were cultured in 96-well plate and divided into 5 groups: OGD, OGD + NC mimic, OGD + $\mathrm{NC}$ inhibitor, OGD + miR-16 mimic, and OGD + miR-16 inhibitor groups. Then, each group was added with cell counting kit-8 (CCK-8) reagent (Solarbio). After $1.5 \mathrm{~h}$ of incubation, and absorbance $(450 \mathrm{~nm})$ was measured with a microplate reader.
Quantitative real-time polymerase chain reaction (qRT-PCR)

The TRIzol reagent (Thermo Fisher Scientific) was selected to extract total RNA. Subsequently, TaqMan microRNA assay kit (Applied Biosystems) and Prime Script RT reagent kit (Takara) were used for reverse transcription of the RNAs to cDNAs which were then subjected to qRT-PCR using SYBR Green PCR kit (Toyobo). Primer sequences were listed in Table 1. The mRNA expressions of AKT3 and miR-16 were normalized with U6 and GAPDH, and calculated with the $2^{-\Delta \Delta C t}$ method.

Table 1: Primer sequences used for qRT-PCR

\begin{tabular}{ll}
\hline Gene & Primer sequence (5'-3') \\
\hline miR-16 & F: TAGCAGCACGTAAATATTGGCG \\
& R: TGCGTGTCGTGGAGTC \\
U6 & F: CTCGCTTCGGCAGCACA \\
& R: AACGCTTCACGAATTTGCGT \\
AKT3 & F: TCCTTCCAGACAAAAGACCGT \\
& R: CGCTCATGATGACTCCCCTC \\
GAPDH & F: AGAAGGCTGGGGCTCATTTG \\
& R: AGGGGCCATCCACAGTCTTC \\
\hline
\end{tabular}

\section{Luciferase reporter assay}

Targets of miR-16 were predicted through TargetScan online software (http://www.target scan.org). The AKT3 was predicted as a potential target gene. Wild type (WT) and mutant type (MUT) dual luciferase reporter vectors (Promega) of AKT3-3'UTR were constructed. Then, the co-transfection of miR-16 mimic and the WT or MUT were performed by Lipofectamine 2000 (Invitrogen). After transfection for $48 \mathrm{~h}$, luciferase activities were assayed with a dual-luciferase assay kit (Promega).

\section{Western blot assay}

Total protein was extracted with RIPA buffer. Proteins were separated using $10 \%$ SDS-PAGE, and transferred onto PVDF membrane. The membrane was then blocked in $5 \%$ skimmed milk at room temperature. Thereafter, the membrane was incubated with primary antibodies (Bax, Bcl-2 and GAPDH), followed by incubation with horseradish peroxidase-labeled secondary antibody. Finally, signals were detected using an enhanced chemiluminescence kit.

\section{Statistical analysis}

All data are presented as mean \pm standard deviation (SD). Statistical analysis was performed with SPSS 16.0 software (IBM). 
Student's $t$-test or one-way analysis of variance (ANOVA) was used to compare the differences. $P<0.05$ was considered statistically significant.

\section{RESULTS}

\section{MiR-16 was up-regulated following OGD treatment}

The expression of miR-16 was increased in OGD-exposed neurons (Figure $1 \mathrm{~A}$ ). The use of mimic or inhibitor to upregulate or inhibit miR-16 expression in OGD-exposed neurons revealed that that increased miR-16 expression may contribute to OGD-induced neuronal injury (Figure $1 \mathrm{~B}$ ).
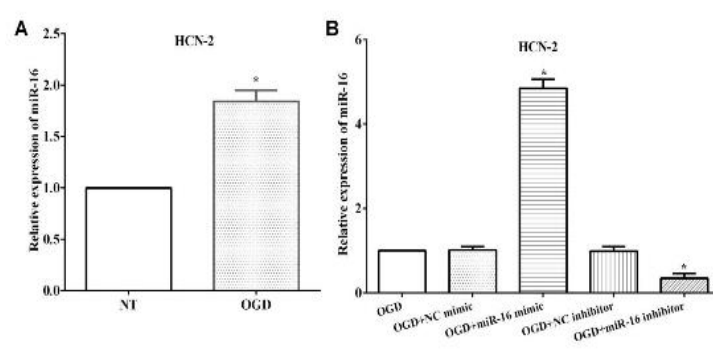

Figure 1: MiR-16 expression after OGD treatment. A: miR-16 expression in OGD-exposed cells, as determined using RT-qPCR. B: After miR-16 mimic or inhibitor transfection, miR-16 expression in OGDexposed cells

\section{MiR-16 enhanced cell viability and inhibited cell apoptosis}

From the results of CCK-8 assay, it was discovered that OGD treatment decreased cell proliferative capacity (Figure 2 A). In contrast, miR-16 mimic improved cell viability, while miR16 inhibitor suppressed same after OGD exposure (Figure 2 B). In addition, cell apoptotic ability was determined based on the expressions of Bax and Bcl-2. It was found that Bax expression was enhanced, while Bcl-2 expression was reduced, on exposure of the cells to OGD (Figure $2 \mathrm{C}$ ). Bax and Bcl-2 expressions were also calculated after overexpression or knockdown of miR-16. Results indicated that miR-16 mimic promoted $\mathrm{Bcl}-2$ expression, while it inhibited Bax expression in OGD-exposed cells (Figure 2 D). In contrast, Bcl2 was downregulated, while Bax was upregulated by miR-16 inhibitor of OGD-treated cells (Figure $2 \mathrm{E}$ ). Western blotting showed results similar to those from $\mathrm{RT}$-qPCR, i.e., miR16 mimic promoted $\mathrm{Bcl}-2$ protein expression, while it suppressed Bax protein expression, with the reverse trend for miR-16 inhibitor (Figure 2 $F)$. These results suggest that miR-16 reduced
OGD-induced apoptosis. Thus, miR-16 regulated OGD-induced neuronal damage.
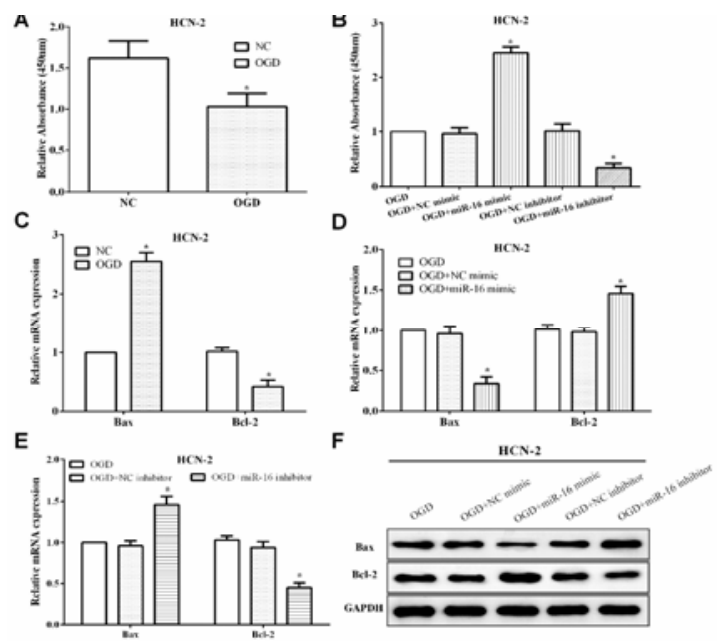

Figure 2: MiR-16 promoted $\mathrm{HCN}-2$ cell proliferation and restrained apoptosis. A: Proliferation of OGDexposed cells, as measured using CCK8 assay. B: Cell proliferation was detected after miR-16 mimic or inhibitor transfection. C, D, E and F: Expressions of apoptosis-related genes after miR-16 overexpression or inhibition in OGD-exposed cells

\section{MiR-16 could target AKT3}

To identify the molecular mechanism involved in the role of miR-16 in cerebral ischemia, potential targets of were predicted by Targetscan online software. Interestingly, binding site were existed between miR-16 and AKT3 (Figure 3A). As expected, luciferase activity was reduced by WT and miR-16 mimic co-transfection, but there were no changes in others (Figure $3 \mathrm{~B}$ ). To confirm AKT3 as a downstream gene of miR-16, AKT3 expression was measured after altering miR-16 in $\mathrm{HCN}-2$ cells. It was found that AKT3 expression was reduced by miR-16 mimic, whereas it was increased by miR-16 inhibitor in $\mathrm{HCN}-2$ cells (Figure $3 \mathrm{C}$ ). These data demonstrate that miR-16 regulated AKT3 expression via targeted binding to AKT3.

\section{AKT3 suppressed neuronal cell viability and promoted cell apoptosis}

AKT3 expression was measured in cells after OGD treatment using qRT-PCR. In contrast to miR-16, AKT3 expression was inhibited in OGDtreated cells compared with normal cells (Figure 4 A). Furthermore, AKT3 expression was evaluated after overexpressing or inhibiting miR16 in OGD-treated cells. As shown in Figure 4 B, pcDNA3.1-AKT3 enhanced AKT3 expression, while siRNA-AKT3 reduced the expression of AKT3 in OGD-treated cells (Figure $4 \mathrm{~B}$ ). Cell 
viability was determined after AKT3 overexpression or inhibition in OGD-treated cells. As expected, AKT3 upregulation inhibited viability, while AKT3 downregulation enhanced viability of OGD-exposed cells (Figure $4 \mathrm{C}$ ). The expression of Bax was promoted by overexpression of AKT3, while it was impaired by knockdown of AKT3 in OGD-treated cells (Figure 4D). In contrast, Bcl-2 expression was suppressed by AKT3 overexpression, while it was enhanced by siRNA-AKT3 in OGD-treated cells (Figure $4 \mathrm{E}$ ), suggesting that AKT3 may enhance $\mathrm{HCN}-2$ cell apoptosis. Moreover, the protein expression level of AKT3 was consistent with qRT-PCR results (Figure $4 \mathrm{~F}$ ). These results indicate that AKT3 may suppress the viability of $\mathrm{HCN}-2$ cells and promote their apoptosis.

\section{AKT3 reversed the effect of miR-16 on cerebral ischemia}

To further confirm whether miR-16 regulated neuronal cell viability and apoptosis via AKT3, AKT3 was downregulated in $\mathrm{HCN}-2$ cells that overexpressed miR-16 (Figure $5 \mathrm{~A}$ ). Results from CCK-8 assay demonstrated that AKT3 counteracted miR-16 mimic's enhancing effect on cell proliferation in OGD-exposed cells (Figure 5B). In addition, Bax and Bcl-2 expressions were measured. It was found that Bax expression was enhanced, while that of Bcl-2 was inhibited after co-transfection with miR-16 mimic and pcDNA3.1-AKT3 (Figures $5 \mathrm{C}$ and $5 \mathrm{D})$, indicating that AKT3 overexpression reversed the enhancing effect of miR-16 mimic on cerebral ischemia. These findings indicate that miR-16 regulated cerebral ischemic injury through targeting of AKT3.

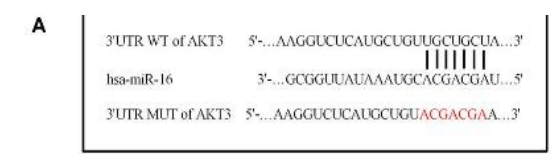

B

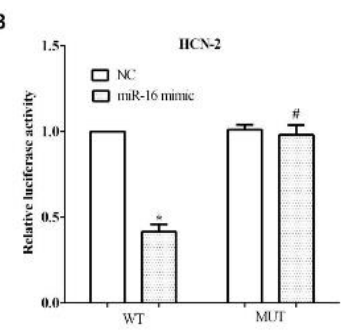

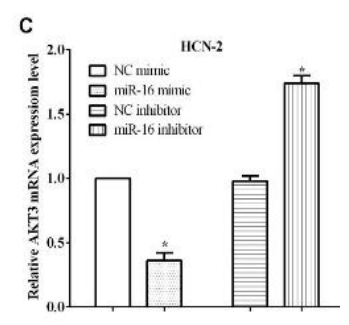

Figure 3: MiR-16 directly targeted AKT3. A: Binding site of miR-16 in AKT3, as predicted using TargetScan. B: Luciferase activity in $\mathrm{HCN}-2$ cells. C: AKT3 mRNA was detected after miR-16 overexpression or inhibition in cells after OGD exposure

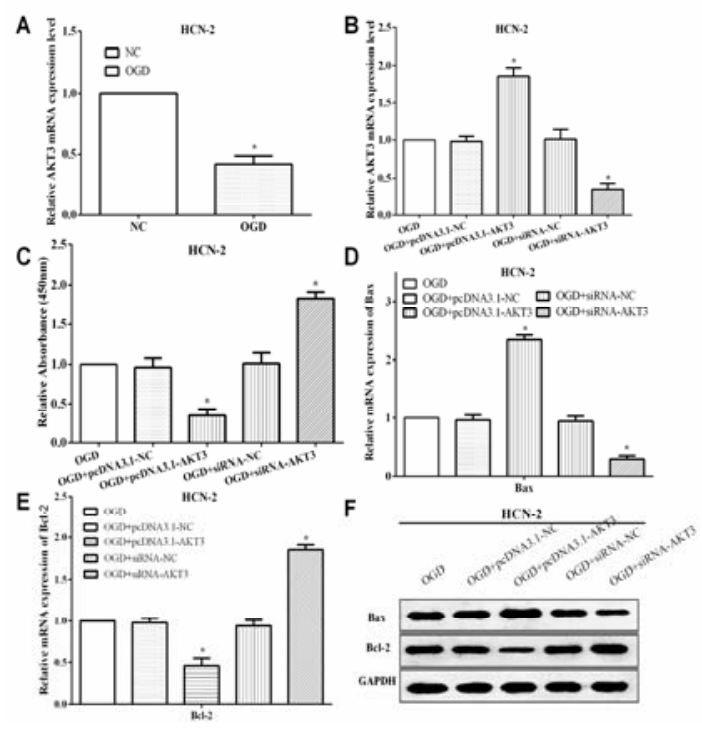

Figure 4: Effect of AKT3 on neuronal cell viability and apoptosis. A: AKT3 expression in OGD-treated cells. $\mathrm{B}$ : AKT3 expression after overexpressing or inhibiting miR-16 in OGD-treated cells. C: AKT3 inhibited viability of OGD-exposed cells. $D, E$, and $F$ : Expressions of apoptosis-related genes after overexpression or inhibition of AKT3 expression

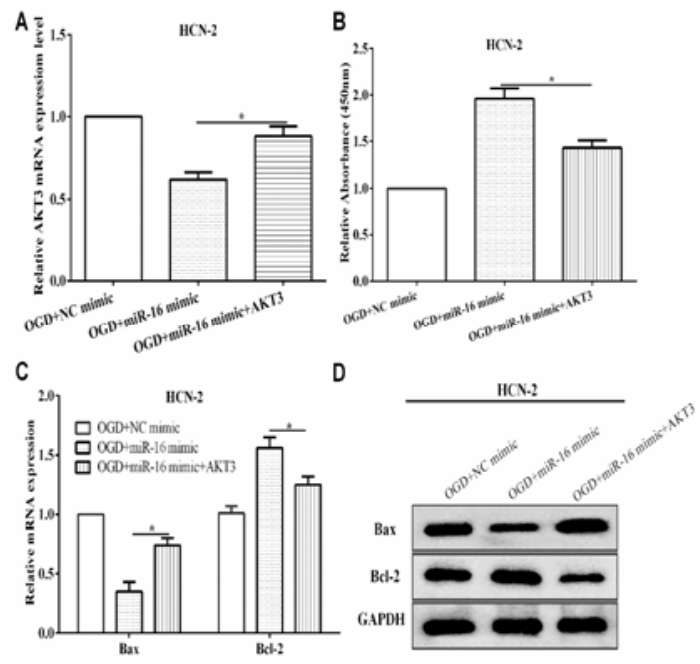

Figure 5: AKT3 reversed miR-16's effect on cerebral ischemia. A: AKT3 was overexpressed in $\mathrm{HCN}-2$ cells with miR-16 overexpression. B: AKT3 overexpression impaired the enhancing of miR-16 mimic on proliferation under OGD condition. C \& D: Bax and $\mathrm{Bcl}-2$ expressions were measured after miR-16 and AKT3 overexpression

\section{DISCUSSION}

Cerebral ischemia induces various pathological pathways, and eventually leads to irreversible injury in the ischemic region [11]. More and more attention has been focused on apoptosis in 
cerebral ischemia [12]. Thus, an understanding of the mechanisms associated with neuronal apoptosis is a very important issue at present.

It is known that miRNAs related to cerebral ischemia may provide new insights into the treatment of stroke. For example, it has been reported that the potential of $\mathrm{miR}-145$ as a biomarker was upregulated in cerebral ischemia [13]. Moreover, inhibition of miR-429 attenuated neuronal injury induced by OGD/R via regulation of GATA4 [14]. Moreover, a previous study revealed that downregulation of miR-30a-induced neuroprotection from ischemic damage by regulating HSPA5 expression [15].

In addition, studies have shown that miR-16 acts as a diagnostic, stratification, and prognosis biomarker of hyperacute cerebral infarction [16]. Consistent with these findings, miR-16 was found to be upregulated in $\mathrm{HCN}-2$ neuronal cells after OGD treatment in the present study. Importantly, miR-16 significantly aggravated ischemic injury via enhancement of cell proliferation. Moreover, miR-16 suppressed $\mathrm{HCN}-2$ cell apoptosis by enhancing $\mathrm{Bcl}-2$ expression and inhibiting Bax expression, suggesting that miR-16 might be a therapeutic target of cerebral infarction.

It is known that AKT3, also named PKB, is involved in various biological processes [17]. It has been reported that in stroke-induced neuronal injury, AKT3 activated phosphorylation of AKT and mTOR compared with AKT1 [18]. In this study, AKT3 was predicted as a target for miR-16 gene in HCN-2 cells. Additionally, AKT3 was downregulated in cells after OGD treatment. Overexpression of AKT3 inhibited $\mathrm{HCN}-2$ cells proliferation and enhanced their apoptosis via regulating $\mathrm{Bax}$ and $\mathrm{Bcl}-2$ expression after OGD treatment. Moreover, AKT3 overexpression partially offset functions of miR-16 on cells proliferation and apoptosis after OGD treatment.

\section{CONCLUSION}

The findings of this study show that miR-16 is upregulated in OGD-treated cortical neurons and that it promotes the proliferation of neuronal cells, while inhibiting apoptosis. In addition, the results indicate that miR-16 targets AKT3, and also that AKT3 expression is regulated by miR16. Therefore, miR-16 may promote cortical neuronal proliferation and inhibit cortical neuronal apoptosis via regulation of AKT3 expression. However, there is need for further studies to provide in vivo evidence for the relationship between miR-16 and AKT3 in ischemic brain injury.

\section{DECLARATIONS}

\section{Conflict of Interest}

No conflict of interest associated with this work.

\section{Contribution of Authors}

We declare that this work was done by the authors named in this manuscript, and all liabilities pertaining to claims relating to the content of this article will be borne by the authors. Yijun Song conceived and designed the study, and drafted the manuscript. Bo Wang collected, analyzed and interpreted the experimental data. Yijun Song revised the manuscript for important intellectual content. Both authors read and approved the final manuscript. Yijun Song and Bo Wang contributed equally to this work.

\section{Open Access}

This is an Open Access article that uses a funding model which does not charge readers or their institutions for access and distributed under the terms of the Creative Commons Attribution License (http://creativecommons.org/licenses/by/ 4.0) and the Budapest Open Access Initiative (http://www.budapestopenaccessinitiative.org/rea d), which permit unrestricted use, distribution, and reproduction in any medium, provided the original work is properly credited.

\section{REFERENCES}

1. Tsai CF, Thomas B, Sudlow CL. Epidemiology of stroke and its subtypes in Chinese vs white populations: a systematic review. Neurology 2013; 81(3): 264-272.

2. Lanz J, Brophy JM, Therrien J, Kaouache M, Guo L, Marelli AJ. Stroke in Adults With Congenital Heart Disease: Incidence, Cumulative Risk, and Predictors. Circulation 2015; 132(25): 2385-2394.

3. Guo YW, Li PY, Guo QL, Shang KX, Yan D, Du SY, Lu Y. Pathophysiology and Biomarkers in Acute Ischemic Stroke-A Review. Trop J Pharm Res 2013; 12(6): 1097.

4. Sun K, Lai EC. Adult-specific functions of animal microRNAs. Nat Rev Genet 2013; 14(8): 535-548.

5. Bulygin KV, Beeraka NM, Saitgareeva AR, Nikolenko VN, Gareev I, Beylerli O, Akhmadeeva LR, Mikhaleva LM, Torres Solis LF, Solís Herrera A, et al. Can miRNAs Be Considered as Diagnostic and Therapeutic Molecules in Ischemic Stroke Pathogenesis? Current Status. Int J Mol Sci 2020; 21(18): 6728.

6. Huang EY, Liu RH, Chu YW. miRNA-15a/16: as tumor suppressors and more. Future Oncol 2015; 11(16): 2351-2363. 
7. Wang F, Mao A, Tang J, Zhang Q, Yan J, Wang Y, Di C, Gan L, Sun C, Zhang H. microRNA-16-5p enhances radiosensitivity through modulating Cyclin D1/E1-pRbE2F1 pathway in prostate cancer cells. J Cell Physiol 2019; 234(8): 13182-13190.

8. Fu X, He $Y$, Wang $X$, Peng $D$, Chen $X$, Li X, Wan $Q$. MicroRNA-16 Promotes Ovarian Granulosa Cell Proliferation and Suppresses Apoptosis Through Targeting PDCD4 in Polycystic Ovarian Syndrome. Cell Physiol Biochem 2018; 48(2): 670-682.

9. Gonzalez-Robayna IJ, Falender $A E$, Ochsner $S$, Firestone GL, Richards JS. Follicle-Stimulating hormone (FSH) stimulates phosphorylation and activation of protein kinase $B$ (PKB/Akt) and serum and glucocorticoid-induced kinase (Sgk): evidence for $A$ kinase-independent signaling by FSH in granulosa cells. Mol Endocrinol 2000; 14(8): 1283-1300.

10. Kim M, Kim YY, Jee HJ, Bae SS, Jeong NY, Um JH, Yun J. Akt3 knockdown induces mitochondrial dysfunction in human cancer cells. Acta Biochim Biophys Sin (Shanghai) 2016; 48(5): 447-453.

11. Zhou L, Li F, Xu HB, Luo CX, Wu HY, Zhu MM, Lu W, Ji $X$, Zhou QG, Zhu DY. Treatment of cerebral ischemia by disrupting ischemia-induced interaction of nNOS with PSD-95. Nat Med 2010; 16(12): 1439-1443.

12. Yuan J. Neuroprotective strategies targeting apoptotic and necrotic cell death for stroke. Apoptosis 2009; 14(4): 469-477.
13. Gan CS, Wang CW, Tan KS. Circulatory microRNA-145 expression is increased in cerebral ischemia. Genet Mol Res 2012; 11(1): 147-152.

14. Xiao J, Kong $R$, Hu J. Inhibition of microRNA-429 attenuates oxygen-glucose deprivation/reoxygenationinduced neuronal injury by promoting expression of GATA-binding protein 4. Neuroreport 2018; 29(9): 723730.

15. Wang P, Zhang N, Liang J, Li J, Han S, Li J. Micro-RNA30a regulates ischemia-induced cell death by targeting heat shock protein HSPA5 in primary cultured cortical neurons and mouse brain after stroke. $J$ Neurosci Res 2015; 93(11): 1756-1768.

16. Tian C, Li Z, Yang Z, Huang Q, Liu J, Hong B. Plasma MicroRNA-16 is a Biomarker for Diagnosis, Stratification, and Prognosis of Hyperacute Cerebral Infarction. PLoS One 2016; 11(11): e0166688.

17. Murthy SS, Tosolini A, Taguchi T, Testa JR. Mapping of $A K T 3$, encoding a member of the Akt/protein kinase $B$ family, to human and rodent chromosomes by fluorescence in situ hybridization. Cytogenet Cell Genet 2000; 88(1-2): 38-40.

18. Xie R, Cheng M, Li M, Xiong X, Daadi M, Sapolsky RM, Zhao H. Akt isoforms differentially protect against stroke-induced neuronal injury by regulating mTOR activities. J Cereb Blood Flow Metab 2013; 33(12): 1875-1885. 